Foreword

\title{
Why should we take an interest in what happens in
} Antarctica?

\section{Oran R. Young}

When asked to identify cases of success in the realm of international environmental governance, most of us who think about such things include the Antarctic Treaty System (ATS) as one of a handful of cases that together constitute the gold standard in this realm. Signed in December 1959 during the height of the cold war, the Antarctic Treaty not only suspended competition among a number of states regarding jurisdictional claims to slices of Antarctica; it also demilitarized the continent, thereby partially exempting it from the most vigorous and ongoing competition between the superpowers for power and influence in most other parts of the world. The complex regime that has developed on the foundation provided by the initial treaty, has proven resilient, responding to various pressures for change by adding substantive components as needed (for example, the 1980 Convention on the Conservation of Antarctic Marine Living Resources, the 1991 Environmental Protocol) and finding new ways to interpret important provisions (for example, the criteria for granting additional signatories to the Antarctic Treaty the status of Contracting Party) to adjust to changing realities in international society. There are not many other international governance systems that can match the ATS's record of effectiveness over a long period of time.

Needless to say, the ATS is not perfect. Critics can and do point to a variety of shortcomings. A number of parties have made use of military personnel and equipment in the construction and supply of research stations and in the deployment of scientists and scientific instruments to research sites. This challenges the claims made by ATS devotees who claim that the continent is free from taint of militarism. The so-called claimant states have not abandoned their jurisdictional ambitions, as exemplified by various statements regarding jurisdiction over the seabed/continental shelf in waters adjacent to Antarctica's coasts. In March 2016, Argentina and the UK resurrected their smoldering territorial conflicts in the South Atlantic and Antarctica, in the aftermath of claims that Argentina's sovereign rights to the seabed included the Falkland Islands and South Georgia. The recommendations by a little known UN Commission on the Limits of the Continental Shelf became headline news around the world for a week or so. In reality the Commission did not 'recommend' that Argentina's sovereign rights extended over the continental shelf adjacent to the Falkland Islands/Malvinas. Thinly disguised economic and political motivations underlie decisions about the location and the scale of some of the scientific research stations. Others have pointed to those responsible for the operation of the research stations and argued that they have not always adhered to high standards of environmental protection in disposing of wastes and obsolete equipment. In the process, the gloss of science and the overall scientific prestige to the workings of the ATS have been diminished. There is some gap between the ideal and the actual in the operation of 
every governance system. And the fact remains that the ATS has proven successful with regard to its fundamental goals of peace, scientific co-operation, resource management and international goodwill. Antarctica remains a peaceful continent with human activities taking place under a well-developed regulatory framework.

Like any successful governance system, the ATS has shown some capacity to adapt to changing circumstances. It could be argued that the ATS has endured precisely because it has not altered and adapted as much as might have been expected, especially after the entry into force of the Protocol on Environmental Protection in 1998. Perhaps the most fundamental and ultimately the most significant development in the life of this governance system remains the abandonment of the Convention on the Regulation of Antarctic Mineral Resource Activities (CRAMRA) adopted in 1988 following extensive negotiations and the adoption of the Environmental Protocol to the Antarctic Treaty in 1991 following comparatively brief negotiations. CRAMRA, which failed to enter into force as a component of the ATS, would have allowed economic development in Antarctica under the terms of a highly innovative regulatory system involving, among other things, the allocation of some of the proceeds from any mining occurring in Antarctica to cover the costs of administering the governance system. The Environmental Protocol, by contrast, begins by stating in Article 2 that the Parties 'hereby designate Antarctica as a natural reserve, devoted to peace and science.' It then proceeds in Article 7 to state clearly and succinctly that '[a]ny activity relating to mineral resources, other than scientific research, shall be prohibited.' What we see here is not only a shift from one laboriously negotiated treaty text to another, but also a transformative switch from one underlying discourse to another. CRAMRA is rooted in the discourse of conservation, a way of thinking that sanctions the consumptive use of natural resources, albeit in this case under a regulatory regime that would have imposed unusually strict limitations on those engaged in extractive activities. The Environmental Protocol, by contrast, reflects a preservationist discourse, a way of thinking that rejects the consumptive uses of natural resources such as oil, gas, coal, and minerals. But it is important to be clear that science is not an end in itself in this context. It is an instrument to be used on the part of those seeking to ensure that Antarctica remains a 'natural reserve' that does not become a locus for the pursuit of economic and political objectives of the sort that underlie human activities in most parts of the world.

Arguably the preservationist ethic of the 1990s has been eroded and it would not be questionable to claim that the Protocol led to a water-shed change in the governance of Antarctica. There are some worrying signs - the sorts of ideas and practices associated with liability, environmental impact assessment and limited commercialization have by and large tilted away from the formal content and spirit of the Protocol. But will this switch prove sustainable under the circumstances likely to unfold at the global level during the coming decades. Contemplating both the challenge of feeding a human population of more than 10 billion people and the consequences of expected geopolitical shifts in international society, some analysts have come to the conclusion that the preservationist vision embedded in the Environmental Protocol cannot survive, even to the end of the current ban on mineral activity in 2049. The consumptive juggernaut of industrialized and industrializing societies, they assert, will simply overwhelm the preservationist arrangement adopted in 1991. Others, pointing to the probable impacts of climate change in the south polar region, argue that Antarctica is likely to experience profound biophysical change over the coming decades that will overwhelm the arrangements embedded in the ATS. 
Under the circumstances, it may become increasingly difficult to know what it means for the continent to be 'devoted to peace and science' on a lasting basis.

Still, it is important not to be swept away by the assumption that structural and material forces will inevitably undermine the preservationist discourse underlying the Environmental Protocol. The fundamental issue here concerns the normative discourses underlying governance systems and the principles that will guide human/nature relations as we move deeper into the Anthropocene. Are we doomed to a world in which the pressures of population growth, industrialization, and rampant consumerism continue to grow unchecked, producing a situation in which we ransack even the most remote areas of the planet for the resources needed to support this materialistic way of life on a continuing basis? Or is there a prospect that shocks arising from transgressing 'planetary boundaries' will set in motion fundamental changes in the normative discourses we employ to think about human development and about the place of human societies within the Earth System? Might we succeed in moving toward a new discourse of stewardship that would place bounds on consumptive uses of natural resources, without prohibiting such uses altogether? Of course, we cannot answer these questions at this juncture. But there are good reasons to believe that an effort to grapple with such concerns will come to occupy a central place in debates about the role of human actions as driving forces in the Earth System during the decades to come.

Antarctica along with other previously remote areas such as the deep seabed and outer space is playing a central role in these debates. With the ending of remoteness, it is no longer appropriate to dismiss what happens in a place like Antarctica as having little to teach us about the broader issues. It may, in fact, prove easier to sort out the pros and cons of new ways to organize our thinking about human/environment interactions in situations that are comparatively simple and that allow us to focus on the core issues without the distractions that cloud our thinking regarding more mainstream concerns. Naturally, any insights we are able to derive from this process would require translation to make them applicable to mainstream debates occurring in both domestic and international settings. Looked at in this way, it is easy to grasp why we should take an interest in what happens in Antarctica. But as this Handbook makes abundantly clear, that opportunity is slipping away. 